\title{
Research on possibilities for monitoring stability of adjacent slopes to transport routes
}

\author{
Aurelian Nicola, Marin Silviu Nan, Adrian Schiopu, Ionela Grecea* , and Daniel Matei \\ ${ }^{1}$ University of Petrosani, 20 University Street, 332006, Petrosani, Romania
}

\begin{abstract}
Development of human society also implies modernization, respectively extension a road and railway transport structures. From this perspective, in order to achieve performance in the field of traffic safety, actions are also required to monitor the slopes, tailings dumps (active or greened) adjacent to transport routes where there are uncertainties regarding their stability. Ignoring stability and landslides can lead to loss of life, as well as significant material damage. Thus, the paper mainly addresses the issue of monitoring the slopes adjacent to road and rail transport routes where there are uncertainties regarding the control of landslides, as well as possibility of alerting before this occurs. From the multitude of possible solutions to be applied in the field, an equipment was developed and realized, which was experienced in real working conditions, and the results confirm validity of assumptions and certify the operation.
\end{abstract}

\section{Introduction}

Stability of slopes adjacent to transport routes is important due to the disastrous effects it can generate in case of landslides, Figure 1. [1] The necessary measures (monitoring or stabilization of slopes) are imperative, their lack can directly affect constructions executed on some sections (bridges, viaducts, etc. Figure 2), or the road be it road or rail, Figure 3, generating significant costs and long time for repair.

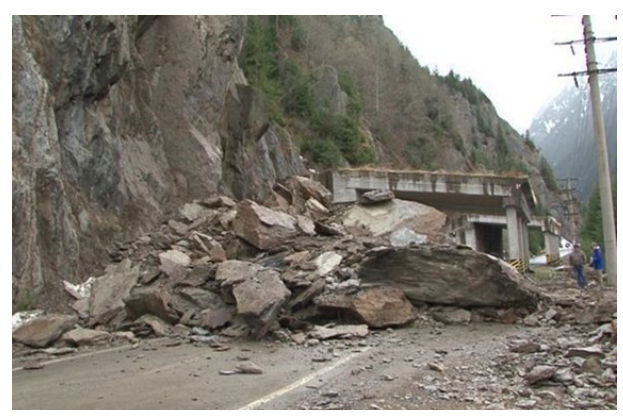

Fig. 1. Landslide on Transfagarasan, 2012.

\footnotetext{
*Corresponding author: ionelagrecea@yahoo.com
} 


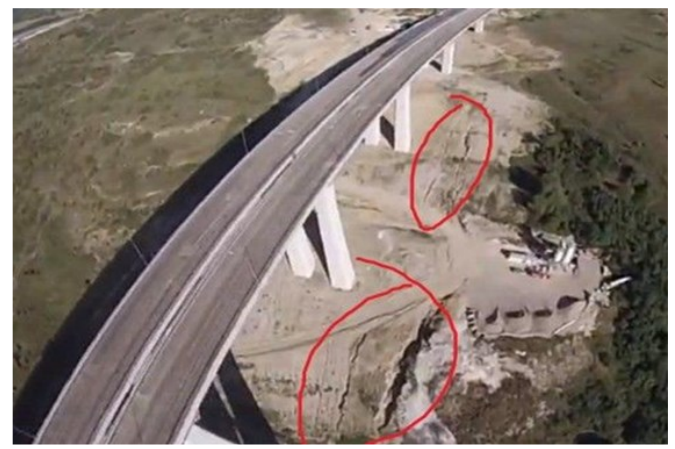

Fig. 2. Landslide on construction site of Orastie - Sibiu highway.

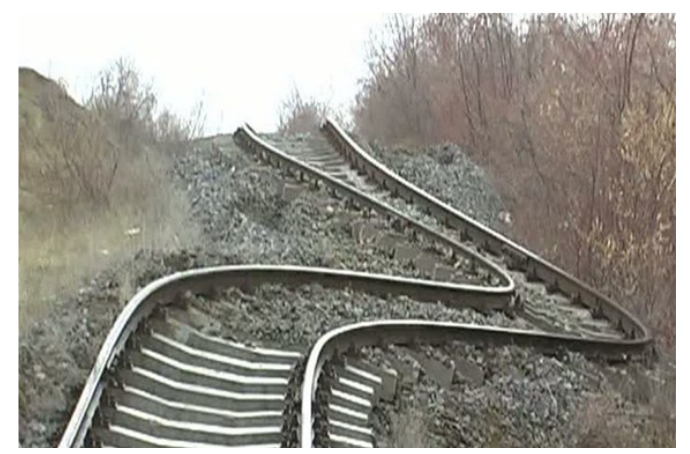

Fig. 3. Landslide in Galati County, 2014

Social impact is important, being able to destabilize the activities of an important community. Also, the impact on environment is negatively influenced, the traffic on detours generating higher amounts of noxious substances. Alternative transport routes affect transport costs and transit times leading to financial losses. [2, 3]

\section{Landslide monitoring methods}

Stages of monitoring process require an interdisciplinary approach and must include the following steps:

- direct observations on the studied area - thus phenomenon can be identified with maximum accuracy;

- field data collection involves measurements and tests in the studied area;

- data processing involves the processing of data collected from the field, using specialized equipment and programs;

- data interpretation is most important and difficult stage of monitoring, a correct interpretation of processed data will certainly lead to results that reflect reality, while a misinterpretation will certainly lead to erroneous solutions;

- technical and economic analysis, is an important factor in choosing technical solutions that will be applied to stabilize the slopes or slopes taking into account economic considerations;

- conclusions and recommendations, represent final stage of monitoring process, refer to concrete situation in the field, to solutions adapted both from a technical and economic point of view, as well as possibilities of integrating adopted solution in an early warning system, etc. [4-6] 


\subsection{Landslide monitoring using total station}

This is the classic, most common method. Using total station, Figure 4, coordinates of points are determined, generating results with high accuracy. Use of this method requires the existence of a basic geodetic network and a reference system.

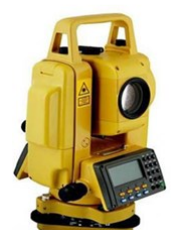

Fig. 4. The total station.

\subsection{Landslide monitoring using GPS system}

GPS systems assume the existence of a satellites constellation that generate signals received by a GPS receiver. The main GPS systems are: NAVSTAR Global Positioning System American system; GLONASS - the Russian system; GALILEO - the European system.

GPS system consists of three basic elements:

- space system - consisting of satellites and signal transmitted by satellite;

- control system - consisting of master stations and control stations;

- user system - consisting of the equipment used.

The system's satellites transmit synchronized time signals using two carrier frequencies, position parameters and other additional information. Constellation of satellites guarantees visibility of at least four satellites from any point on the earth. Signals emitted by satellites, through those Figure 5, two carriers reach GPS receiver on the ground.

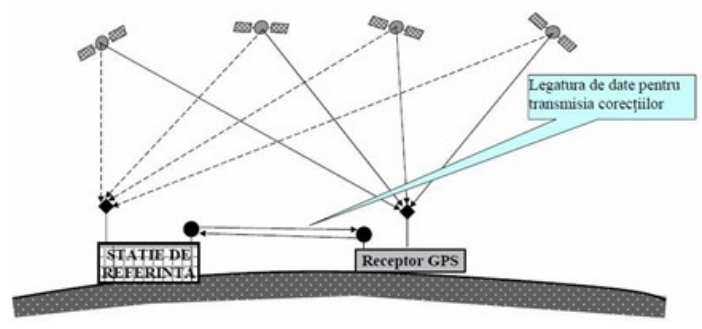

Fig. 5. GPS differential positioning method.

GPS receiver calculates its position by determining the time made from satellite to receiver. Satellites have high-precision watches (with rubidium, caesium or hydrogen Maser). By determining the time taken from each satellite received (minimum 4), GPS receiver can determine its position with an accuracy of $1 \mathrm{~m}$.

In order to increase accuracy, differential positioning method is used, by using reference stations, the accuracy reaching order for tens of centimetres.

\subsection{Landslide monitoring using images}

In evolution of photogrammetry, methods of collecting analogue data were noticed, later appearing the digital method which practically revolutionized photogrammetry. Images collected by this method are called frames. 
As a monitoring method, slopes and valleys are carefully analysed, so areas with potential hazard can be identified. Potentially hazardous areas differ from the overall picture by darker contour lines, usually semi-circular in shape. We can also highlight some circular or elliptical areas that represent areas with higher humidity (puddles, lakes), also in some cases, even vegetation on disturbed slope differs from surrounding vegetation.

Frames can be obtained using fixed terrestrial devices (geophotogrammetry) or by using cameras mounted on an aerial vehicle (aerial photogrammetry), Figure 6.

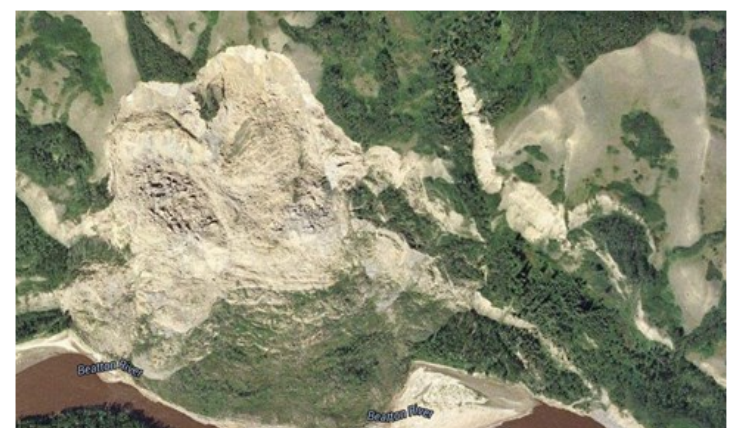

Fig. 6. Air photogrammetric.

\subsection{Landslide monitoring by remote sensing}

Satellite images have recently become of very good quality, which makes it possible for them to provide information on landslides, especially in monitoring slopes or large areas of land. An advantage of this method is that images are provided at short intervals, so the dynamic phenomena can be followed.

The equipment used is called a scanning imager radiometer that emits electromagnetic waves and then receives and processes the reflection of waves on the earth's surface. Depending on the wavelength used, remote sensing satellites can be: infrared; optical or microwave.

Images obtained by these methods are digital and can be used for analysis: brightness; colour; textural information; geometric and contextual. Another advantage of using radar systems is their ability to work regardless of weather conditions, day or night.

INSAR technology is a recent image processing technique provided by on-board SAR radar sensors. The final products obtained through INSAR are: terrain deformation maps, digital elevation models. By processing the products provided by this technology, movements at ground level can be highlighted, as a result of human or natural activity. The technology is applicable for large areas, being able to perform measurements in thousands of points, obtaining complex information, impossible to obtain through classical procedures due to its size or hard to reach places. The accuracy of the measurements is of the order of $\mathrm{mm} /$ year. LIDAR is an optical technology for remote exploration, with the help of which information about the studied objects can be extracted by interpreting the light scattered on the distant objects. Images obtained, Figure 7, are of remarkable precision, of the order of centimetres. The LIDAR method uses 3 basic systems: laser scanning for the best possible distance measurement, global positioning system (GPS) and Inertial Measurement Unit (IMU) for recording orientation. Laser scanning is used to measure the time differences between the laser pulses sent from the plane and those reflected by the topographic surface. GPS system installed in the plane it records the position of the plane, using also a permanent GPS station located at ground level, to increase the positioning accuracy (differential GPS 
system). The IMU unit consists of a set of gyroscopes and accelerometers that continuously measure height, acceleration, plane.

The technology is similar to the radar system, the difference being given by the wavelength used. LIDAR systems use wavelengths of $1.3-1.1 \mu m$ (i.e., the entire visible spectrum), while radar systems use wavelengths of the order of $\mu m \ldots \mathrm{mm}$.

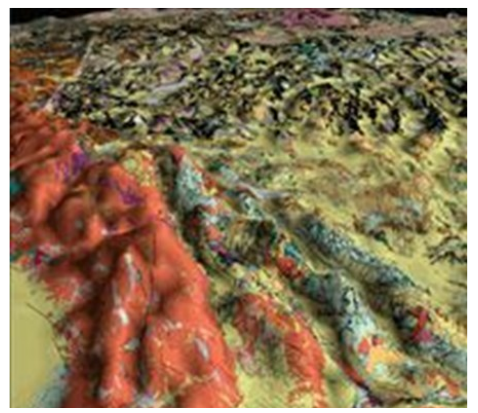

Fig. 7. Image obtained using LIDAR technology.

\subsection{Landslide monitoring using direct measurements}

These monitoring methods differ only in the type of sensor installed in the studied rock mass. As mounting methods, we mention:

- measurements performed with flexible piping, Figure 8. a), which involves execution of drilling in the studied area. The boreholes must exceed sliding surface by a few meters, embedding themselves in stable rock. A plastic tube is inserted in drill hole which has guide grooves for inclinometer probe inside. A material with characteristics closes to that of the ground in study area is inserted between wall of the borehole and plastic tube in order to prevent the free movement of tube in borehole, thus avoiding reading errors.

Inclinometer is inserted inside the plastic tube and values are read at intervals of $0.5-$ $1 m$, and the read values must be carefully preserved over time. Their comparison leads to an analysis of displacement as a function of depth. The large number of boreholes ensures an accurate picture of the sliding mass.

- measurements performed using piezometers. An important factor in determining landslides is the water pressure in the pores. Piezometers, Figure 8. b), are used for this purpose and are in the form of a sealed device, inserted into the ground.

In practice, piezometers are installed in boreholes only to determine the groundwater level, as well as its seasonal fluctuations, because through observation wells a connection is created between the layers, which makes water pressure can no longer be read at real values, from each layer.

- measurements performed using extensometers. Extensometers, Figure 8. c), are devices used to monitor the change in distance between points on a common axis. [6]
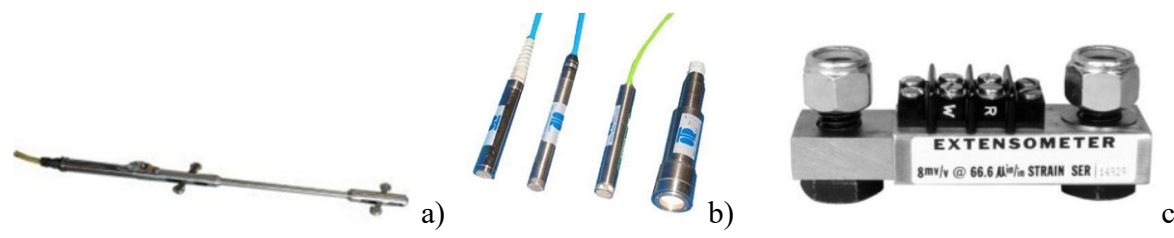

c)

Fig. 8. a) Inclinometer, b) Piezometers, c) Extensometer. 


\section{Design, construction and testing of a landslide monitoring installation}

Realization of a monitoring installation involves a sustained activity starting from its design, to its commissioning and operation. In recent years, progress of technology has facilitated emergence of devices that help researcher, who can benefit from performance of detection and interconnection with other devices. [7]

The correct choice of these devices and technologies makes it possible to create and design a monitoring equipment in accordance with the technological advances of recent years, even if the methods of analysis for terrain stability are known long ago.

Monitoring phenomena underlying landslides must follow the following steps:

- establishing the block diagram of general operation for monitoring;

- gathering information from the source (from the field);

- primary processing of raw information;

- transmission of partially processed information to server;

- final processing of information;

- interpreting results, establishing the alert thresholds;

- the actual alert;

There are two variants of the block scheme. Figure 9-a), refers to the block operation diagram of installation, used in the field and Figure 9-b) an equipment in laboratory.

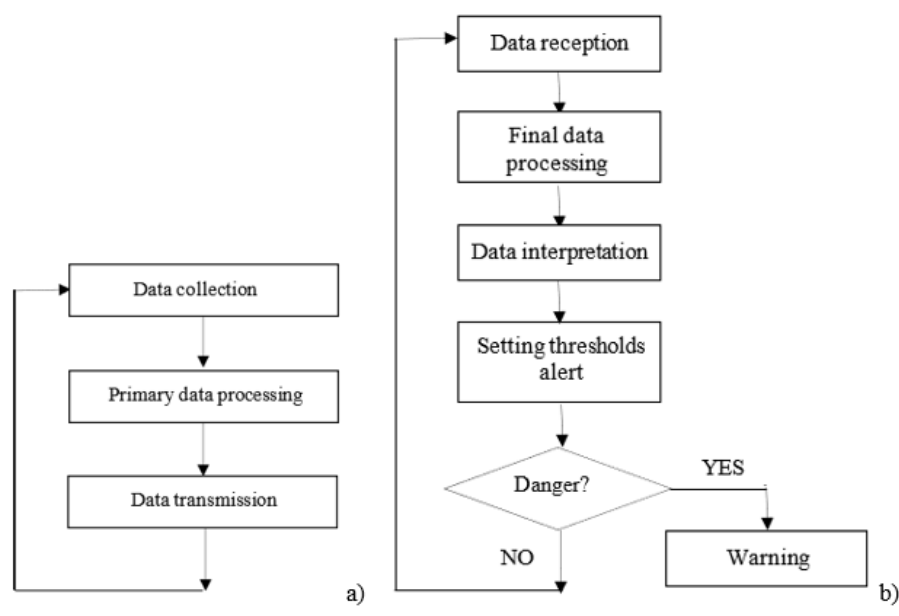

Fig. 9. Block diagram of operation: a) an installation used in the field; b) an equipment in laboratory.

Data collection is the first step in monitoring process and is materialized in reading sensors, or as the case may be, in taking photo, coordinates in the case of total station. This stage is of major importance in assessing the final results, as the errors introduced in system at this stage are amplified as next steps are taken. Primary data processing has the role of reducing volume of data to be transmitted to command-and-control centre, in order to reduce the operating costs of the installation. The final part, data transmission, sends preliminary results to command and control centre. Process is resumes cyclically, at predetermined time intervals.

Second variant, Figure 9-b), refers to monitoring installation used in laboratory. Reception of data must be compatible with the mode of transmission used by the field installation. Final processing is to sort, and display data in an easy-to-read and useful format for the next step. Interpretation is when it is determined what changes are in the 
field. Depending on default alert thresholds, the alert decision is made. If there are no changes, the process resumes. [8]

Creation, design and construction of monitoring installations are mandatory stages of this process, on which results of research depend to a large extent. Clear establishment of some objectives to be achieved in monitoring process, makes whole process have a logic, and appropriate choice of methods and equipment used ultimately leads to expected results. These monitors usually analyse previous events and, on their basis, a further evolution of situation on the ground is forecast. However, the human factor is most important because, usually, interpretation of the results is done by specialists.

In order to achieve the proposed monitoring equipment, it is necessary to comply with certain restrictions on energy consumption, equipment price, installation method, reliability, etc. So, all chosen equipment has a low energy consumption, a sufficiently high computing power, due to the fact that landslides are slow-moving phenomena, have a low volume to be able to be mounted in a small enclosure, with a high degree weather protection. Power supply is made from a solar panel, with appropriate dimensions, which is able to charge a battery with a large enough capacity to power the equipment used and if the weather conditions are not favourable for several days in a row. Data transmission to laboratory is done using the GSM network available in area, and the data is processed primarily so that the volume to be transmitted is small, this transfer will be done using SMS, block diagram show in Figure 10 and proposed monitoring installation is presented in Figure 11. [9-10]

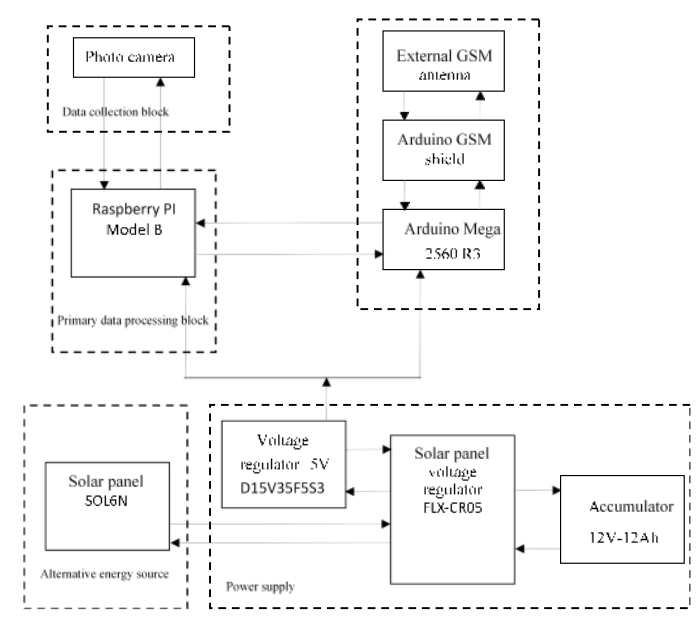

Fig. 10. Block diagram of operation for equipment in the field.
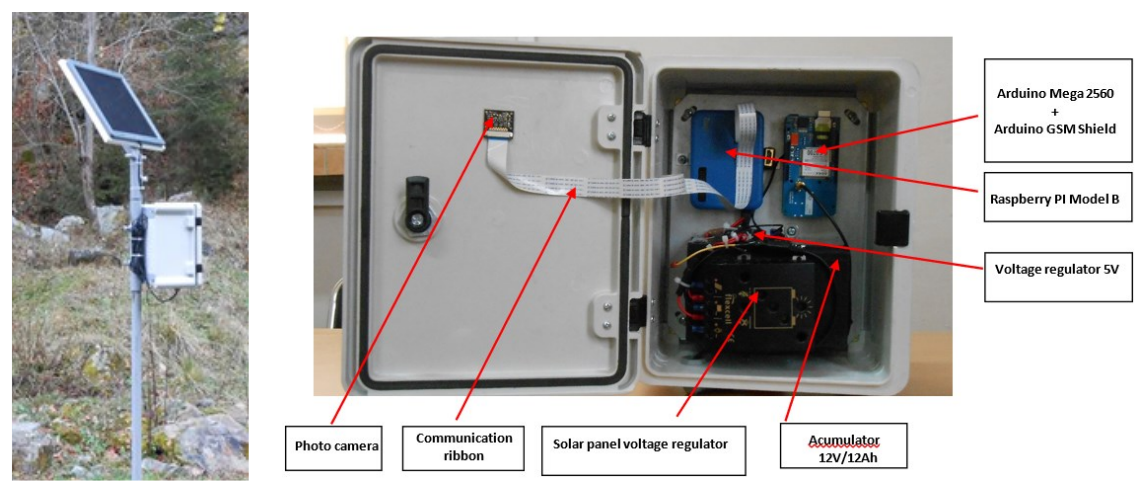

Fig. 11. Monitoring equipment mounted in „situ”. 
The monitored area and installation of equipment being in mountains, in an isolated area, this area is located near the Mija Chalet, on road that connects Petrosani to Voineasa, on the Jiet gorge.

In order to monitor, an imaging solution was chosen, and in the area subject to monitoring, three panels measuring $70 \mathrm{~cm} \times 80 \mathrm{~cm}$ were installed, hereinafter referred to as "markers" and two panels of $50 \mathrm{~cm} \times 50 \mathrm{~cm}$ considered as a landmark or points of reference. Panels were arranged as in Figure 12. Width of monitored area is approximately $39 \mathrm{~m}$, and the height $29.5 \mathrm{~m}$, measured on the ground, in a straight line, between the edges of captured image.
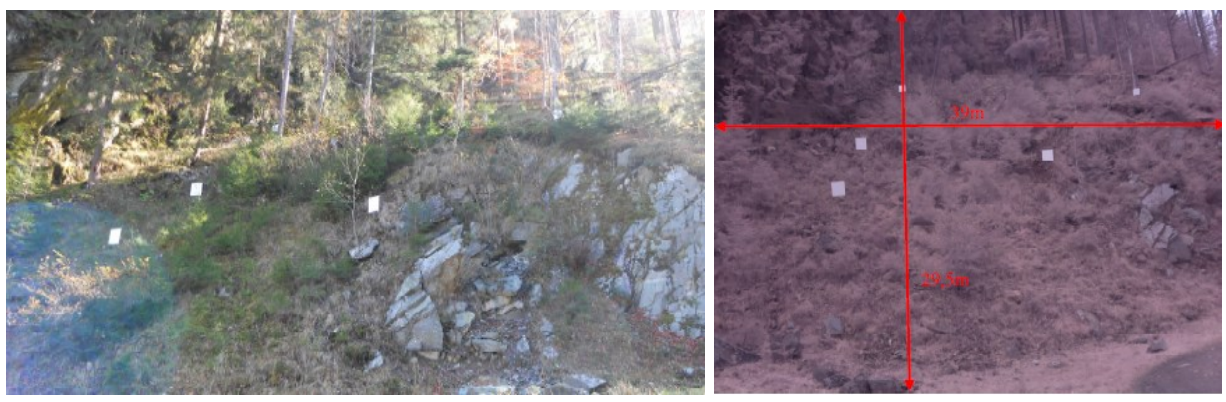

Fig. 12. Image and dimensions of monitoring area, with the panels installed.

Distance between chamber and base of slope influences the way directly the accuracy of measurements, in this case being $30 \mathrm{~m}$. Increasing these distances can be compensated with use of a camera with high resolution or use of optical lenses.

The work steps for monitoring are as follows:

a) Photographing area subject to monitoring using infrared camera, Figure 13-a), at a resolution of $5 \mathrm{MP}(2592 \times 1944 \mathrm{px})$;

b) Convert the captured image to black and white format, Figure 13-b), this conversion is needed for easier identification of panels;

c) Determining coordinates of the centre for each panel and preparing data for transmission. These operations were performed with help Raspberry Pi microcontroller;

d) Transmission of data to laboratory by ARDUINO M2560 through the GSM network.
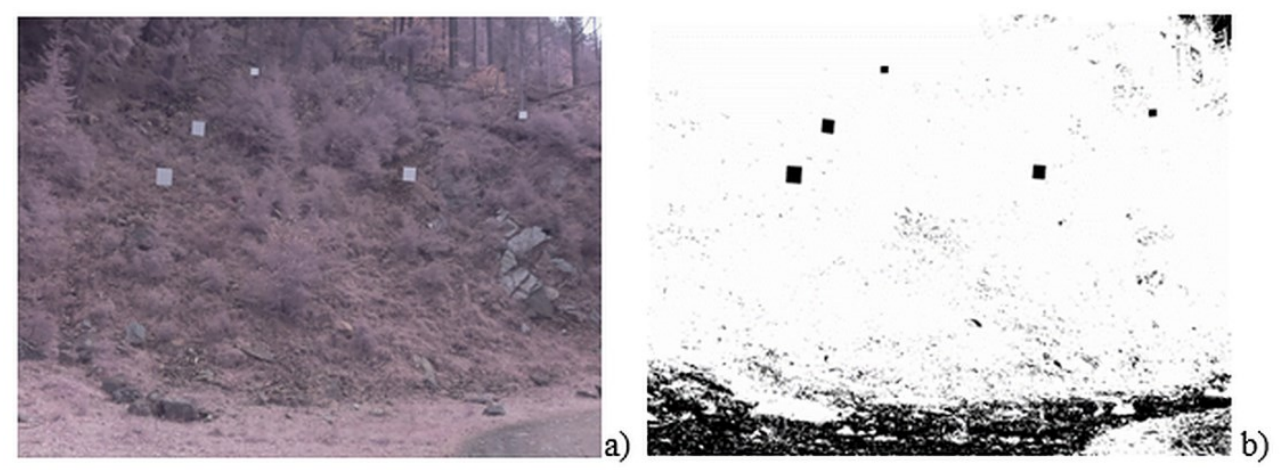

Fig. 13. Image: a) obtained in infrared; b) converted to black and white.

A GSM modem, compatible with frequency, was used for data reception and a personal computer was used to process data. The received SMS message contains five pairs of coordinates, $(x, y)$, corresponding to the 5 panels installed in situ. The first two pairs belong to the control panels, and the next three correspond to the marker panels. 
By graphic method and with help of trigonometry, the transmitted coordinates of centres for the 5 monitored panels, following analysis and processing, according to the geometric shape shown in Figure 14, the results obtained are shown in Figure 15.

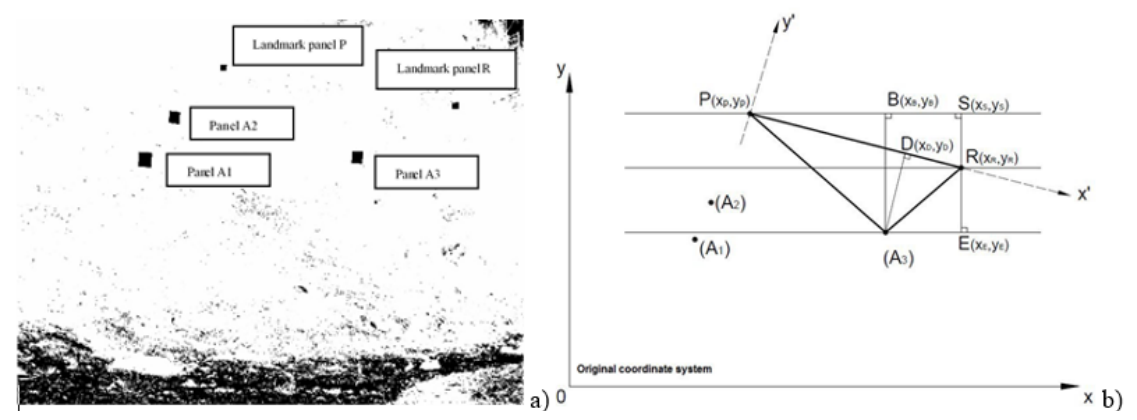

Fig. 14. Arrangement of panels in the field. a) real image converted to black and white; b) calculation scheme.
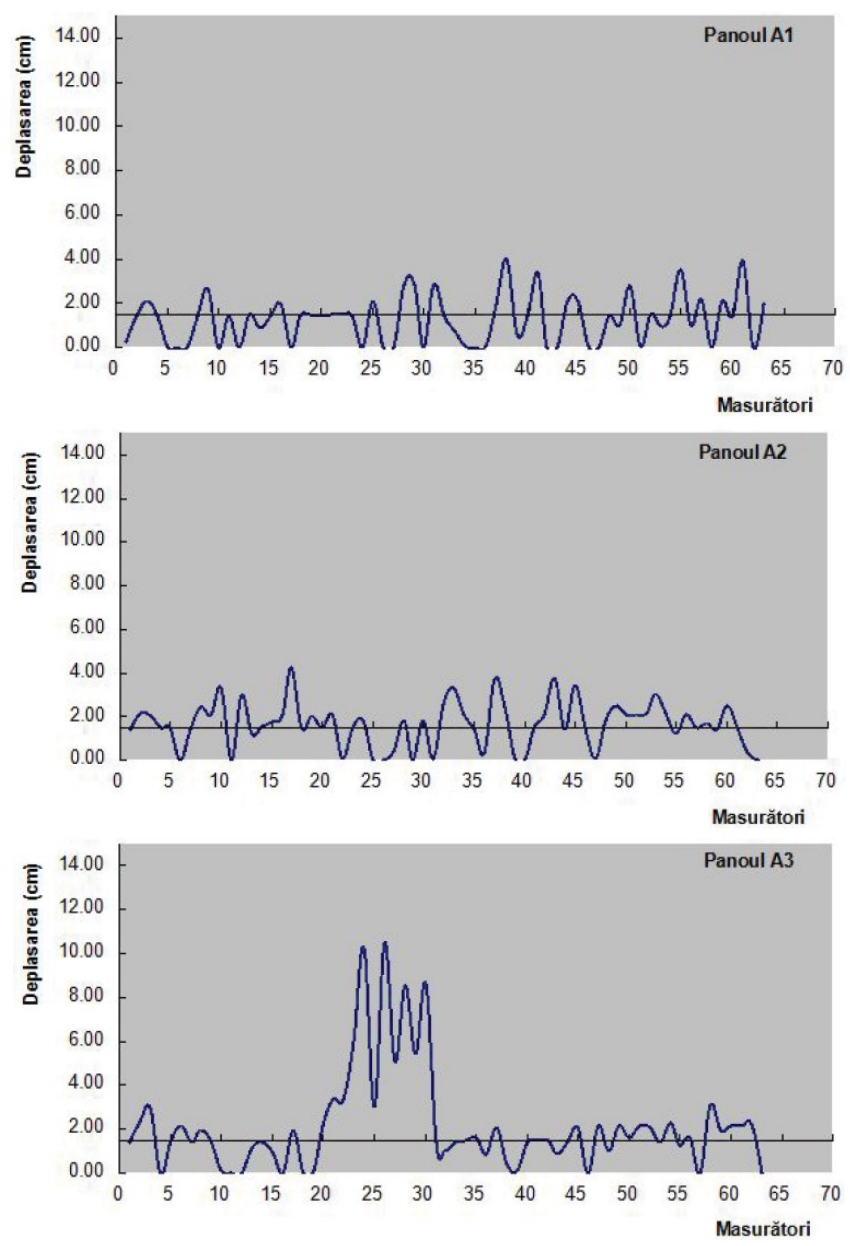

Fig. 15. Graphical representation of movement, recorded during the monitorisation. 
In this phase, equipment could be evaluated in terms of functionality continuously, without human intervention. The monitoring was performed within 2 weeks.

The data transmitted by equipment, presented graphically, indicates an oscillation of coordinates for panels around the axis, but cause of this is in imperfections of image processing, especially when the panels are identified. The corners of panels being automatically identified the positioning error is \pm 1 pixel. This error also depends on the light level at moment taking the picture.

During the monitoring, panels A1 and A2 remained fixed, only the panel A3 registered a movement for a few days, then the ground stabilized. Correlating the movement with the existing weather conditions in that period, following the monitoring it is found that the movement occurred during a rainy period, when, including Hunedoara County was under yellow rain code. In this case, it is clear that heavy rains have been a factor in landslides. Studying the location of the marker panels, it is observed that panels A1 and A2 are located in an area with vegetation (grass and shrubs), and panel A3 is positioned in an area without vegetation, showing that it has a special importance in soil stabilization.

\section{Conclusions}

Monitoring areas where landslides are possible highlights future landslide processes, thus allowing specialists and responsible factors to implement certain optimal methods of stabilizing slopes or mountainsides, which ultimately lead to minimal material damage and specially to save humanly lives.

For high-risk areas near transport routes, automatic alerting can be done by remotely controlling the illuminated information panels above the road, but this decision must be made by a person who has skills in assessing landslides and can do automatically through various data transmission methods: GSM, internet, etc., but only after setting alarm thresholds to avoid false alarm.

The combination of various monitoring methods also leads to improved results. Experience of human operators is also very important in interpreting the data from equipment used. Man, due to his complexity, is the only one who can make important decisions in order to close a section of road or railway at an alert indicated by the equipment in field.

\section{References}

1. J.A. Smethurst, A. Smith et al., QJEGH, 50, 3 (2017)

2. M.S. Nan, T. Iacob Ridzi, L.D. Dandea, Teoria sistemelor de transport (ED Universitas, Petrosani, 2012)

3. M.S. Nan, D. Grecea, A. Nicola, E.I. Grigore, Sisteme de transport urban si periurban (ED Universitas, Petrosani, 2019)

4. M.S. Nan, A. Parvu, D. Parvu, P. Grigore, D. Grecea Managementul, calitatea si fenomenele fizice în poluarea mediului (ED Universitas, Petrosani, 2019Standard SR EN 60079-1 (2014)

5. Q.P. Luozang, J.J. Gan, F. Zhou, L.G. Xin, ESCE'20, A Multiple Method of Monitoring for Rainfall Induced Landslide, (Nanchang, China, 2020)

6. C.I. Colda, M.S. Nan, D. Grecea, Structura sistemelor de monitorizare utilizate în exploatarile la $z i$ (ED INSEMEX, Petrosani, 2018)

7. N.Jiang, H.B. Li, Q.J. Kou, J.W. Zhou, Geomatics natural hazards \& risk, 12, 1 (2021)

8. A. Schiopu, M.S. Nan, ICAI'14, Research for designing and experimenting the equipment for monitoring slopes adjacent roads and rail, (Geneva, Switzerland, 2014)

9. https://www.raspberrypi.org/, [Accessed 21.05.2020]

10. https://www.oracle.com/technical-resources/articles/java/raspberrypi.html,[Accessed 25.05.2020] 